\title{
SELF-CARE OF FRONTLINE HEALTH CARE WORKERS: DURING COVID-19 PANDEMIC
}

\author{
Maria Waris Nawaz ${ }^{1}$, Shumaila Imtiaz ${ }^{2}$ \& Erum Kausar ${ }^{1}$ \\ ${ }^{1}$ Institute of Professional Psychology, Bahria University Karachi Campus, Karachi, Pakistan \\ ${ }^{2}$ Quaid-i-Azam University Islamabad, Islamabad, Pakistan
}

received: 29.6.2020;

revised: 27.7.2020;

accepted: 17.9.2020

\section{SUMMARY}

The world is amidst the COVID-19 pandemic that has used social distancing as a tool for containing the virus from spreading exponentially among other individuals. Previous literature suggests that human contact and attachment is a key for well-being which is why punishments like solitary confinement in detention centers like jail has always been debated as being torturous (Wolfendal 2020). With this notion, anxiety and stress may become more prevalent in individuals who experience self-isolation or are under a forced lockdown. For health-care workers like doctors and psychologists, who advocate for physical health, mental health and wellbeing; the challenges might increase during the pandemic phase as they are expected to go through the crises just like others while simultaneously contributing in rendering services related to dealing with physical and psychological health issues present in patients and clients with their continued practice from either on-site or online platforms. Although all health care professional's training inoculates the ill effects of compassion fatigue by other's overwhelming situations and discussions but they might still be prone to vicarious burnout, trauma and stress. Hence, they may become exposed to being at risk of experiencing anxiety more than the general population. This review discusses facets of the importance of self-care as mental health first aid tool for health care professionals including doctors and psychologists using research and supportive techniques to help them process stress and anxiety during and after the global pandemic.

Key words: self care - health care professionals - psychologists - mental wellbeing - COVID-19

$* * * * *$

\section{INTRODUCTION}

The global pandemic, COVID 19 has put a pause on all kinds of activities taking place around the globe which include activities related to academics, work, leisure or recreation (World Health Organization 2020). By the months of March and April 2020, almost all the countries had already started the drills for closing their travelling and trade while making this global village turn into a field limited to just themselves (Devi 2020). Over the past 5 months, it has been clearly seen that almost all the countries have called COVID-19 as an emergency because of the increased number of patients after being tested as corona positive, the hospitals have seen more patients than the tourists on popular leisure destinations, the sudden need of ventilators had increased to facilitate patients breathing who otherwise would be called to their final abode after being critically ill (Spinelli \& Pellino 2020). According to Jakovljevic (2020) the pandemic has been tough and as expected, a range of longterm negative mental health consequences might have been faced by individuals especially the frontline healthcare workers, who not only stood as frontline warriors but also as supportive gears for their families and their patients while trying best to guard themselves from the virus. Hence, this article focuses on using certain selfcare techniques as mental health first aid which would help health care workers to deal with compassion fatigue that might drain and deteriorate their psychological wellbeing during and after the COVID-19 pandemic.

\section{CLINICAL VIGNETTES}

\section{A 27-year-old female}

She is a MBBS Doctor and a front line health worker in the COVID-19 isolation ward. She has a family of 8 and is set to get married in December 2020 with beautiful plans for her life ahead. In April 2020, her duty roster changed and she was asked to work for COVID-19 patients, following this her concerns regarding taking precautionary measures against COVID-19 increased due to which, she experienced symptoms of anxiety mainly because of the worry related to contracting with any of the patients or bringing COVID-19 at home with her through surface transmission. She has been quite despondent about her medical practice because of her Hippocratic oath and also financially meeting her household requirements during the pandemic. Being the eldest daughter and independently taking care of the family has laid a lot of pressure on her during this vulnerable time when she is expected to professionally deal with her patients under ethical standards, help them manage and cure their symptoms while normally deal with the pandemic like everyone else around the globe. She explained that time has been very difficult for her after the outbreak of COVID-19 because the weather in Karachi has been between 37 to 45 degrees during day time, and wearing PPE suit has been quite rough for her. She also mentioned that, during the post-duty timing, she has become quite apprehensive as she has been covering her 
face and frequently washes hands after coming home. Further, she explained that her anxiety symptoms and being paranoid about surface transmission has made her mind to overthink, consequently making her struggle in adopting healthy coping mechanisms.

\section{A-28-year-old male}

He is a Dentist and has been working as a front-line Health Care Assistant (HCA) in the COVID-19 isolation ward at the Karachi Expo Center from over a month. He explained that before the outbreak of COVID-19, life was very different as all of his worries included taking out time for his family and friends, researching about the advances in his field or how to work towards his goals, which now he reckoned to be "too simple" as he further added that after the outburst of COVID-19, his basic worry includes survival, of not just himself but also of his family, especially when he has a mother who is diabetic and has to be cared for more than any other healthy individual. He believed that although death is inevitable and everyone has to face it someday so there is nothing to fear about it but, death as a result of COVID-19 entails bigger sacrifices, where the dead body is not handed over to the family for performing final rituals as per the Islamic norms which are mandatory for any Muslim or even having a blessed last sight of the deceased loved one. Under such circumstances, the family is left devastated, he recalled an incident and shared how a family had broken a riot in a private hospital in Karachi when the hospital authorities had refused to give the dead body of a COVID-19 positive patient to the family. His experience of serving at an isolation ward had taught him the importance of one breath which separates life from death altogether. For his coping, he mentioned that during his 8 hour shift at the ward he looks forward to treating and managing the patients which in return pray for him and this serves as the main motivating factor for him, with this he also has recurring thoughts related to taking precautions and restlessness from enclosing himself within the sealed PPE outfit. This causes him to experience some discomfort during the time when he is with the patients, or on his way to home and even right before sleeping to wake up for another day in order to go back to the patients, but he mentioned that spirituality and the feeling of being appreciated has made him to continue to do what he has been doing and he hopes that the world comes out of this situation sooner and stronger.

\section{A-36-year-old female}

She is a Clinical Psychologist $\mathrm{PhD}$. and has been working as a mental health practitioner for the COVID19 patients and their families in a private hospital in Karachi, Pakistan, where she has also been giving telepsychotherapy to COVID-19 patients. She explained that she was tested twice for COVID-19 by the hospital management but luckily her tests came out to be negative. For her, the whole testing experience was quite painful as she faced nose bleeding after the nasal swab was removed from her nose which had caused a lot of anxiety to her. She further mentioned that, "Psychologists are expected to be objective while not letting their emotions get in their way of work but at the end they are humans too, and such unloading of emotional insecurities and fears of others especially during a pandemic can have detrimental effects on their own well-being". For her, life has been about spreading positivity amidst the outbreak of COVID-19, which had sometimes become very difficult for her because she has been counseling families for issues related to grief, especially those families who have been struggling with getting closure for the death of their loved ones because they did not think that after getting admitted to the hospital, a healthy individual with some mild breathing difficulties would later require a ventilator to breathe and eventually die and they would never see their loved one again to bid good bye. She explained how this uncertainty causes trauma and may create a void in them for the rest of their lives. Furthermore, she added that being a witness to all this, she has been dealing with compassion fatigue, burnout and anxiety every day for which, peer supervision has helped her cope with all the overwhelming thoughts and feelings that are generated during the current pandemic situation.

\section{Experiencing Challenges}

The above mentioned psychologist and doctors are not unique at dealing with anxiety as a result of COVID-19, although they are expected to have better coping mechanisms than the rest of the population but even with that, they might be experiencing bereavement or adjustment disorder, depressed mood and mixed anxiety or even vulnerabilities related to sleep and panic with acute stress disorder. Hence, this article discusses quick remedies for health care professionals in order to help them swiftly navigate through the COVID-19 pandemic so that they perform their duties at optimal levels. Also, challenge can be experienced when individuals use blaming as an escape from the ongoing anxiety rather than thinking and identifying with it, for many it may work well but for many it may create feelings of helplessness and loss of self-control as Active or passive blaming tends to be an inherent feature that human beings possess that helps them shift responsibilities onto other in trying to reduce their own overwhelming feelings (Jakovljevic et al. 2020).

\section{Dealing with uncertainty}

According to another research, suspicion and doubt are present everywhere (Jakovljevic et al. 2019). And since the time when COVID-19 had led people to stay indoors, the people who have been going out of their homes have been under the influence of absolute suspicion and distrust, which means that if in the household or at work someone is tested positive for COVID-19 then it might not just make everyone feel frustrated by to the news but also get angry at the ones 
who have direct contact with the outer world. This suggests that blaming and facing uncertainty to COVID19 situation needs to be given profound attention because once this is sorted only then the care for the patient who has tested positive can be carried out (Jakovljevic et al. 2020).

\section{COMPASSION FATIGUE OF HEALTH WORKERS}

The combination of burnout, trauma, and frustration which comes through a feeling of hopelessness in the daily life of health care workers is called compassion fatigue. Literature suggests that setting boundaries and limits with patient can reduce compassion fatigue (Razai 2020). The current situation of COVID-19 has evoked anxiety and stress among health workers. In particular, health workers may suffer from severe emotional distress which leads to the development of compassionate fatigue (Alharbi et al. 2020). The lack of balance between compassion and work quality of life, as well as the feeling of hopelessness can be described as compassion fatigue (Sullivan et al. 2019). The pandemic has led the rest of the world not only to high viral infection mortality, but also effecting mental health of people (Xiao 2020). In Pakistan, the number of coronavirus cases has been increasing day by day which put health workers under constant physical and mental pressure. The severity of cases and inadequate facility to provide health care has caused anxiety and stress among health workers (Rana et al. 2020). Previous literature suggests that the prevalence rate of anxiety among health workers is $23.2 \%$ and for depression $22.8 \%$. The study also showed that nurses and female doctors have been more vulnerable to affective symptoms in comparison to male doctors and staff (Pappa et al. 2020). Consequently, staff members have also been vulnerable in breaking bad news to the relatives of COVID-19 patients while causing moral injury and producing remorse in the staff members of hospitals which lead to compassion fatigue (Greenberg et al. 2020). Furthermore, previous literature also suggested that significant physical and emotional damage could be found in health workers which may decrease the compassion present in them for serving others, resulting in sleep disturbance, guilt and moral injury which could lead them to increased willingness of leaving the field or dissatisfaction (Kelly et al. 2015).

\section{TECHNIQUES TO ENCOUNTER COMPASSION FATIGUE}

\section{Mindfulness}

Mindfulness can be defined as paying close attention to the surroundings and being non-judgmental to experience different things. Studies have shown practicing mindfulness can recover a person from both physical and mental health conditions including anxiety, stress and depression. Mindfulness-based therapy (MBT) comprises of mindfulness techniques which foster the understanding of non-judgmental actions. At present, it could be particularly helpful for people having physical and psychological conditions, for which it is necessary for them to alleviate stress (Carlson 2012). Mindfulness techniques are helpful for health workers, its endorsed well-being and self-care among them (Duarte \& PintoGouveia 2016). Mindfulness and meditation work as resilience by bringing life satisfaction among health workers. It also lays the foundation of self-compassion in them. Overall, it can be said that mindfulness may improve the quality of life in health workers. In addition, a large number of previous literature supported the positive effects of mindfulness training, minimally suggesting that during the everyday routine, only 10 minutes of mindful meditation while practicing pause may help individuals in reducing anxiety to a greater extent. Furthermore, mindful eating and mindful shower/bath can also help the health care workers to experience positive affect needed to relax their mind and body tension (Geller 2017).

\section{Increase Interpersonal Skills}

Practicing communication skills in the medical profession is essential for effective communication and the development of a trustworthy relationship or rapport thus, it is healthy for both patient and doctor. Previous studies indicate that $15 \%$ of health workers encounter a difficult situation with patients (Jackson \& Kroenke 1999). Also, communication with loved ones or friends is very important in quarantine time as it allows them to reassure their loved ones about health. Therefore, regular contact with family acts as a mode of practicing resilience which helps them fight with compassion fatigue (Manuell \& Cukor 2011). Research also reveals that the training of effective communication skills does decrease job burnout among nurses as it helps them in dealing with emergency and secondary trauma conditions experienced when communicating with patients and their relatives. It also increases productivity and adaptability during overwhelming situations (Darban et al. 2017).

\section{Guided imagery}

One of the relaxation techniques is guided imagery where imagining about soothing places and experiences may calm down anger or frustration. Guided imagery may help individuals to reinforce the positive force. Previous literature suggests that individuals practicing guided imagery may experience good sleep quality and reduced compassion fatigue (Kiley et al. 2018). Besides, 10 weeks of guided imagery study significantly increase self-efficacy and decreases depression and stress (Menzies et al. 2014). Since, stress and anxiety are highly prevalent among health workers so to reduce their stress and anxiety guided imagery can be very 
effective. Not just this, but it also suffices enough to show effectiveness in many fields other than related to health. Consequently, it improves self-efficacy and quality-related burnout which helps to avoid compassion fatigue (Rao \& Kemper 2017). Guided imagery focuses attention on visual, auditory, or other sensory images for therapeutic purposes. Clinical uses include safely reducing acute and chronic pain, reducing preoperative and pre-procedural anxiety, soothing pain, and anxiety in emergency settings (Iserson 2014).

\section{Thought catching}

Burnout and frustration are not just terms but experiences that may cause serious cognitive errors in thinking. These cognitive errors can be detected using the Thoughtful thinking by self-monitoring and reflection when performing tasks when dealing with COVID patients or other patients during a pandemic (Norcross \& Phillips 2020). Questioning about the surroundings would guide the individual to detect cognitive errors and may help them in problem-solving. This questioning might help them to find out the real interpretation of their thoughts, hence giving time to health workers to collect evidence which may make them think positively and may refute to negativity. Over thinking of recurring negative thoughts can also be blocked by self-recording and self-monitoring (Macklem 2010).

\section{Self-care}

Self-care is defined as taking time for oneself to practice things that maintain health and wellbeing. In this time of the pandemic when people have uncertainty and fear for the future, it is worth to take out time for oneself and perform some of the self-care techniques that might be helpful in developing patience needed to understand the seriousness of COVID-19 (Walton et al. 2020). Additionally, self-care increases resilience and decreases frustration and secondary trauma among health workers. There are numerous self-care techniques like taking some time for personalized plans, having proper sleeping hours, massaging, and yoga for anxiety and stress. Practicing yoga with aromatherapy may also make an individual feel relaxed (Blackburn et al. 2020). Also, self-care works as a preventive measure for secondary trauma as it decreases the chances of stress turning into a chronic disorder. Another common practice for self-care is physical exercise where mental health practitioners state that it is an essential part of self-care in order to maintain wellbeing. With that, spirituality is a critical self-care practice as well, since it also brings calmness to an individual when restlessness disrupts their mood (Killian 2008).

\section{Tele/Online- Mental Health Services}

Tele-mental health can be defined as the usage of online platforms and telephone services to deliver mental health care. Brooks et al. (2020) suggested that having online or telephone services for staff and other administrative people working in the health sector will assure them for getting support. They also suggested that online instruction in terms of developing illness will mitigate the anxiety and fear of developing an illness. In another study, a team of mental health professionals was set up at the University of Macau to help the Social Work Office for providing emotional counseling to selfisolated individuals via hotline, chats, and video calls (Li et al. 2020). In many mental health conditions, such as anxiety and depression, the use of online Cognitive Behavior Therapy (CBT) has established itself to be efficient and effective just as the face-to-face CBT. Online CBT can mitigate the stress level and might be helpful in reducing compassion fatigue. The online psychological support given to people a few years back during SARS, was also through telephone lines and had maintained confidentiality of both the health workers and the patients carefully. Presently, mental health workers in Ontario established free online mental health services to health workers who worked with COVID-19 patients (Wu et al. 2020). Previous research has also suggested that having online support for mental health practitioners present under quarantine is effective as it may reduce their anxiety. It may also provide backup support to them to communicate their needs or also reach out to others for help during an emergency easily.

\section{CONCLUSION}

The idea of being there for someone when they are in dire need serves as a sense of fulfillment, it is like going beyond self for others and in return feeling contentment but when the capacity of feeling warmth for others is fully utilized then it may create a conflicting inner self that may not only drain an individual's physical health but also deteriorate their psychological thinking space needed for their wellbeing. Also, religious coping has been one of the factors that encourage empathy by rationalizing the suffering (Jakovljevic et al. 2016), as a test sent by the God and people should not complain but remain patient and pass time, without realizing that this may lead to internalized emotions that may manifest themselves as anxiety when dealing with overwhelming situations (Jakovljevic $2017,2018)$. Hence it is very important for health care workers to maintain balance between their needs and others' needs, which can be easily achieved by practicing techniques mentioned in this article as part of their daily routine.

Acknowledgements: None.

Conflict of interest: None to declare. 


\section{Contribution of individual authors:}

Maria Waris Nawaz: main Idea, concept and design of the article, writing manuscript with continuous reviewing and approval of the final version.

Shumaila Imtiaz: literature search and writing manuscript with continuous reviewing and approval of the final version.

Erum Kausar: supervision and continuous reviewing and approval of the final version.

\section{References}

1. Alharbi J, Jackson D \& Usher K: Personal characteristics, coping strategies and resilience impact on compassion fatigue in critical care nurses: A cross-sectional study. Nursing \& Health Sciences 2020; 22:20-27

2. Blackburn L, Thompson K, Frankenfield R, Harding $A$ \& Lindsey A: The THRIVE ${ }^{\mathcal{O}}$ Program: Building Oncology Nurse Resilience through Self-Care Strategies. In Oncology Nursing Forum 2020; 47:25-34

3. Brooks SK, Webster RK, Smith LE, Woodland L, Wessely $S$, Greenberg $N$ et al.: The psychological impact of quarantine and how to reduce it: rapid review of the evidence. The Lancet 2020; 395:912-920

4. Carlson LE: Mindfulness-based interventions for physical conditions: a narrative review evaluating levels of evidence. International Scholarly Research Notices 2012; 1-21

5. Darban F, Balouchi A, Narouipour A, Safarzaei E \& Shahdadi H: Effect of communication skills training on the burnout of nurses: a cross-sectional study. Journal of Clinical and Diagnostic research 2016; 10:IC01-IC04

6. Devi S: Travel restrictions hampering COVID-19 response. The Lancet 2020; 395:1331-1332

7. Duarte J \& Pinto-Gouveia J: Effectiveness of a mindfulness-based intervention on oncology nurses' burnout and compassion fatigue symptoms: A non-randomized study. International Journal of Nursing Studies 2016; 64:98107

8. Geller SM: A practical guide to cultivating therapeutic presence. American Psychological Association, Washington $D C, 2017$

9. Greenberg N, Docherty M, Gnanapragasam $S \&$ Wessely $S$ : Managing mental health challenges faced by healthcare workers during covid-19 pandemic. The BMJ 2020; 368

10. Iserson KV: An hypnotic suggestion: review of hypnosis for clinical emergency care. The Journal of Emergency Medicine 2014; 46:588-596

11. Jackson JL \& Kroenke K: Difficult patient encounters in the ambulatory clinic: clinical predictors and outcomes. Archives of Internal Medicine 1999; 159:1069-1075

12. Jakovljevic $M$ \& Tomic Z: Global and public mental health promotion for empathic civilisation: The role of political psychocultures. Psychiatr Danub 2016; 28:323333. https://doi.org//10.24869/psyd.2016.323

13. Jakovljevic M: Resilience, psychiatry and religion from public and global mental health perspective - Dialogue and Cooperation in the Search for Humanistic Self, Compassionate Society and Empathic Civilization. Psychiatr Danub 2017; 29:238-244.

https://doi.org//10.24869/psyd.2017.238
14. Jakovljevic M: Empathy, sense of coherence and resilience: Bridging personal, public and global mental health and conceptual synthesis. Psychiatr Danub 2018; 30:380-384. https://doi.org//10.24869/psyd.2018.380

15. Jakovljevic M, Kurjak A, Jerkovic A, Hasanovic A \& Nikic $M$ : Spirituality, religiosity and nationalism from the perspective of public and global mental health. Psychiatr Danub 2019; 31:382-391. https://doi.org/10.24869/psyd.2019.382

16. Jakovljevic M: COVID-19 crisis as a collective hero's journey to better public and global mental health. Psychiatr Danub 2020; 32:3-5. https://doi.org//10.24869/psyd.2020.3

17. Jakovljevic M, Jakovljevic I, Bjedov $S$ \& Jaksic $N$ : COVID-19 pandemia and public and global mental health from the perspective of global health security. Psychiatr Danub 2020; 32:6-14

18. Jakovljevic M, Jakovljevic I, Bjedov $S$ \& Mustac F: Psychiatry for better world: Covid-19 and blame games people play from public and global metal health perspective. Psychiatr Danub 2020; 32:221-228. https://doi.org/10.24869/psyd.2020.221

19. Kelly L, Runge $J \&$ Spencer C: Predictors of compassion fatigue and compassion satisfaction in acute care nurses. Journal of Nursing Scholarship 2015; 47:522-608

20. Kiley KA, Sehgal AR, Neth S, Dolata J, Pike E, Spilsbury $J C$ et al.: The effectiveness of guided imagery in treating compassion fatigue and anxiety of mental health workers. Social Work Research 2018; 42:33-43

21. Killian KD: Helping till it hurts? A multimethod study of compassion fatigue, burnout, and self-care in clinicians working with trauma survivors. Traumatology 2008; 14:32-44

22. Li W, Yang Y, Liu ZH, Zhao YJ, Zhang Q, Zhang L et al.: Progression of mental health services during the COVID19 outbreak in China. International Journal of Biological Sciences 2020; 16:1732-1738

23. Macklem GL: Evidence-based school mental health services: Affect education, emotion regulation training, and cognitive behavioral therapy. Springer Science \& Business Media, Boston MA, 2010

24. Manuell ME \& Cukor J: Mother Nature versus human nature: Public compliance with evacuation and quarantine. Disasters 2011; 35:417-442

25. Menzies V, Lyon DE, Elswick RK, McCain NL \& Gray DP: Effects of guided imagery on bio behavioral factors in women with fibromyalgia. Journal of Behavioral Medicine 2014; 37:70-80

26. Norcross JC \& Phillips CM: Psychologist Self-Care During the Pandemic: Now More Than Ever. Journal of Health Service Psychology 2020; 46: 59-63

27. Pappa S, Ntella V, Giannakas T, Giannakoulis VG, Papoutsi E \& Katsaounou P: Prevalence of depression, anxiety, and insomnia among healthcare workers during the COVID-19 pandemic: A systematic review and metaanalysis. Brain, Behavior, and Immunity 2020; 88:901-907

28. Rana W, Mukhtar $S \&$ \& Mukhtar S: Mental health of medical workers in Pakistan during the pandemic COVID-19 outbreak. Asian Journal of Psychiatry 2020; 51:102080.

29. Rao $N$ \& Kemper KJ: The feasibility and effectiveness of online guided imagery training for health professionals. Journal of Evidence-based Complementary \& Alternative Medicine 2017; 22:54-58 
30. Razai MS, Oakeshott P, Kankam H, Galea S \& StokesLampard H: Mitigating the psychological effects of social isolation during the covid-19 pandemic. The BMJ 2020; 369

31. Spinelli, A \& Pellino G: COVID-19 pandemic: perspectives on an unfolding crisis. The British Journal of Surgery 2020; 107:785-787

32. Sullivan CE, King AR, Holdiness J, Durrell J, Roberts KK, Spencer $C$ et al.: Reducing compassion fatigue in inpatient pediatric oncology nurses. Oncology Nursing Forum 2019; 46:338-347

33. Walton M, Murray E \& Christian MD: Mental health care for medical staff and affiliated healthcare workers during the COVID-19 pandemic. European Heart
Journal: Acute Cardiovascular Care 2020; 9:241-247

34. Wolfendale J: Prison as a Torturous Institution. Res Philosophica 2020; 97:297-324

35. World Health Organization: WHO Director-General's opening remarks at the media briefing on COVID-19. World Health Organization, Geneva, Switzerland, 2020

36. Wu PE, Styra R \& Gold WL: Mitigating the psychological effects of COVID-19 on health care workers. CMAJ 2020; 192:459-460

37. Xiao C: A novel approach of consultation on 2019 novel coronavirus (COVID-19)-related psychological and mental problems: structured letter therapy. Psychiatry Investigation 2020; 17:175-176

Correspondence:

Maria Waris Nawaz, MD

Institute of Professional Psychology, Bahria University Karachi Campus

Karachi, Pakistan

E-mail: mariawaris@outlook.com 